\title{
Genetic parameters for test day somatic cell score in Brazilian Holstein cattle
}

\author{
C.N. Costa' ${ }^{1}$, G.G. Santos ${ }^{1}$, J.A. Cobuci ${ }^{2}$, G. Thompson ${ }^{3,4}$ and J.G.V. Carvalheira ${ }^{3,4}$ \\ ${ }^{1}$ Embrapa Gado de Leite, Juiz de Fora, MG, Brasil \\ 2Departmento de Ciência Animal, Universidade Federal do Rio Grande do Sul, \\ Porto Alegre, RS, Brasil \\ ${ }^{3}$ Instituto de Ciências Biomédicas Abel Salazar, Universidade do Porto, \\ Porto, Portugal \\ ${ }^{4}$ Research Center in Biodiversity and Genetic Resources, University of Porto, \\ Vairão, Portugal \\ Corresponding author: C.N. Costa \\ E-mail: claudio.napolis@embrapa.br \\ Genet. Mol. Res. 14 (4): 19117-19127 (2015) \\ Received August 13, 2015 \\ Accepted October 7, 2015 \\ Published December 29, 2015 \\ DOI http://dx.doi.org/10.4238/2015.December.29.21
}

ABSTRACT. Selection for lower somatic cell count has been included in the breeding objectives of several countries in order to increase resistance to mastitis. Genetic parameters of somatic cell scores (SCS) were estimated from the first lactation test day records of Brazilian Holstein cows using random-regression models with Legendre polynomials (LP) of the order 3-5. Data consisted of 87,711 TD produced by 10,084 cows, sired by 619 bulls calved from 1993 to 2007 . Heritability estimates varied from 0.06 to 0.14 and decreased from the beginning of the lactation up to 60 days in milk (DIM) and increased thereafter to the end of lactation. Genetic correlations between adjacent DIM were very high $(>0.83)$ but decreased to negative values, obtained with LP of order four, between DIM in the extremes of lactation. Despite the favorable trend, genetic changes in SCS were not significant and did not differ among LP. There was little benefit of fitting an LP of an order $>3$ to model animal genetic and permanent environment effects for SCS. Estimates of variance components found in this study may 
be used for breeding value estimation for SCS and selection for mastitis resistance in Holstein cattle in Brazil.

Key words: Dairy cattle; Genetic correlation; Heritability; Random regression; Somatic cell count

\section{INTRODUCTION}

Mastitis is one of the most important diseases in dairy cattle because of large economic losses arising from reduced milk production, increased treatment costs, the disposal of milk, herds, and the culling of cows (Halasa et al., 2007). Mastitis also causes suffering to the animals. Therefore, strategies to reduce mastitis have received increased attention in dairy cattle breeding (Koivula et al., 2004), not only for economic reasons, but also for ethical and animal welfare reasons.

Selection for increased milk yield without simultaneous selection against mastitis resistance will lead to increased susceptibility to mastitis (Rupp and Boichard, 2003). Breeding for increased resistance to mastitis can be performed by direct selection using clinical mastitis records, by indirect selection using traits genetically associated with mastitis, or using a combination of both methods (Heringstad et al., 2000). Direct selection against clinical mastitis (CM) is hard to implement because of its low heritability (Rupp and Boichard, 2003; Carlen et al., 2004) and a lack of recorded incidence data (Mrode and Swanson, 2003) available in few countries.

In the last decade, the somatic cell count (SCC) method has become the most useful indirect measure of mastitis resistance. Selection for lower SCC is consistent with the goal of maximizing genetic improvement for total economic merit and has been included in the breeding objectives of several countries (Mark, 2004; Miglior et al., 2005; Mark and Sullivan, 2006). In most national selection indices, the somatic cell score (SCS), a logarithmic function of SCC, was the only trait found to contribute to udder health (Miglior et al., 2005).

Heritability of SCS is greater than that of CM, with a value around 0.10 , but the efficiency of SCS as a selection criterion to reduce clinical mastitis depends on the genetic correlation between these traits. An average value reported for this parameter is 0.70 , with estimates ranging from 0.30 to 0.90 (Mrode and Swanson, 1996; Carlen et al., 2004; Gernand and König, 2014), supporting the use of SCS to improve genetic resistance to mastitis. Although heritabilities for SCS are low, selection for SCS may be effective and produce improvements by decreasing first-lactation SCS and the frequency of culling for mastitis (Miller et al., 2009).

Initially, studies evaluating the use of SCS to improve genetic resistance to mastitis were based on lactation measures. Implementing the prediction of breeding values for SCS in national evaluations has evolved as an analysis of test day SCS using random regression models (RRM) to estimate the genetic merit of animals (Mrode and Swanson, 2003; Samoré et al., 2008; Mrode et al., 2012). The application of RRM for the estimation of breeding values account for variances and correlations of repeated records of traits that change along a time trajectory. Currently, national genetic evaluations of SCS implemented by most countries include the use of RRM (Interbull, 2013).

In Brazil, genetic evaluations of the Holstein breed only include production and linear type traits (Costa et al., 2013). In recent years, SCC in milk samples of individual cows has been measured on a large scale in national milk recording services. The availability of SCC records makes it possible to obtain genetic parameters with the goal to estimate breeding values for SCS. The aim of this study was to estimate the genetic parameters for test day SCS in the first lactation of Holstein cattle in Brazil. 


\section{MATERIAL AND METHODS}

\section{Data}

Data were extracted from the official milk recording services provided by the Brazilian Holstein Association and were edited to include test day records of first lactating cows with calving dates between 1993 and 2007, and with an age at first calving of 18 to 48 months. Data included Holstein cows defined by two breed compositions: purebred from origin (46\%) and purebred by crossing (upgraded cows, at least the fifth generation of continuous crossing with purebred Holstein bulls, therefore, equal or over $31 / 32$ of Holstein composition). The editing process considered deleting cows having less than eight SCC records in the first lactation and records with $<6$ or $>305$ days in milk (DIM).

Data were also edited for contemporary groups defined by cows in the herd-year-test season (HTS) of recording. Cows belonging to a HTS class with fewer than three records, and from bulls with fewer than three daughters in at least two herds, were removed from the dataset. Four age-at-calving classes (20 to 24,25 to 29,30 to 34 , and 35 to 48 months) and four testing seasons (January to March, April to June, July to September, and October to December) were combined to produce 16 age-season classes. The trait SCC was recorded every month, measured in 1000 cells $/ \mathrm{mL}$ and log transformed to calculate the somatic cell score, SCS $=\log _{2}(S C C / 100,000)+3$. The data structure after editing is shown in Table 1.

\begin{tabular}{|c|c|c|}
\hline Item & Unit & Records \\
\hline Herds & $(\mathrm{N})$ & 732 \\
\hline HTS & $(\mathrm{N})$ & 8,159 \\
\hline Test day records & $(\mathrm{N})$ & 87,711 \\
\hline Average age at first calving & (Months) & $30.20 \pm 6.72$ \\
\hline Average DIM & (Days) & $278.14 \pm 27.08$ \\
\hline Average milk yield & $(\mathrm{kg})$ & $26.53 \pm 7.40$ \\
\hline Average SCC & (1000 cells $/ \mathrm{mL})$ & $221.07 \pm 327.83$ \\
\hline Average SCS & $\left(\log _{2} 1000\right.$ cells $\left./ \mathrm{mL}\right)$ & $2.94 \pm 2.02$ \\
\hline Cows & $(\mathrm{N})$ & 10,084 \\
\hline Bulls & $(\mathrm{N})$ & 619 \\
\hline Animals in pedigree & (N) & 20,205 \\
\hline
\end{tabular}

HTS = herd-year-test season; DIM = days in milk; SCC = somatic cell count; SCS = somatic cell score.

\section{Statistical analyses}

The random-regression model fitted to the data, using Legendre polynomials (LP) of order (degree plus one) three to five (LP3-LP5) to fit fixed, genetic, and permanent environment effects, and assuming homogeneous residual variance was as follows:

$$
\begin{aligned}
& \mathrm{m}-1 \quad \mathrm{~m}-1 \quad \mathrm{~m}-1 \\
& \underset{\mathrm{n}=0}{\mathrm{Y}_{\mathrm{ijj} / \mathrm{k}}=\mathrm{HTS}_{\mathrm{i}}}+\mathrm{B}_{\mathrm{j}}+\sum_{\mathrm{n}=0} \beta_{l m} \varphi_{\mathrm{m}}(\mathrm{t})+\sum_{\mathrm{n}=0} \alpha_{k m} \varphi_{\mathrm{m}}(\mathrm{t})+\sum \gamma_{k m} \varphi_{\mathrm{m}}(\mathrm{t})+\varepsilon_{\mathrm{ijjko}}
\end{aligned}
$$

where $Y_{i j k o}$ is the $o^{\text {th }}$ observation on animal $k$ of breed composition $j$, HTS is the herd-year-test season effect $i ; \beta_{l m}$ is the $m^{\text {th }}$ fixed regression coefficient for $l^{\text {th }}$ age-season, $\alpha_{k m}$ the random genetic, 
and $\gamma_{\mathrm{km}}$ the random environment regression coefficients for animal $k$, respectively, $m$ the order of the polynomial fit, $\varphi_{\mathrm{m}}(\mathrm{t})$ the $m^{\text {th }}$ orthogonal polynomial of DIM, $t$ (standardized in the range -1 to +1 , representing days 6 to 305 ), and $\varepsilon_{\mathrm{ij} \mid \mathrm{ko}}$ is the temporary environment effect associated with the specific test day record.

Covariance components were estimated using the average information from the REML procedure available in the AIREMLF90 program (Misztal, 2007). The convergence criterion was set to $10^{-9}$. Details of the log-likelihood, assumptions, and estimation of variance components using RRM with orthogonal polynomials were defined as presented by Meyer (1998). The fit of different RRMs was compared by examining estimated residual variances, logarithm of the likelihood function, and Akaike's information criterion (AIC; Akaike, 1974). RRMs were also compared by genetic trends obtained by the regression of the weighted averages of predicted SCS breeding values for cows and sires on their respective birth years. Weighting factors were the number of cows and sires born in each birth year.

\section{RESULTS AND DISCUSSION}

\section{Model evaluation}

Estimates of log-likelihood functions, AIC, and residual variance (RV) for the three LP fitted by RRM are presented in Table 2. Values from log-likelihood functions and AIC increased whereas $\mathrm{RV}$ decreased by $6.25 \%$ as the order of LP increased from three to five.

\begin{tabular}{|c|c|c|c|}
\hline Model $^{1}$ & $-2 \log L$ & AIC & Residual variance \\
\hline LP3 & $282,627.2679$ & $282,713.2679$ & 1.078 \\
\hline LP4 & $289,602.8449$ & $289,644.8449$ & 1.035 \\
\hline LP5 & $296,754.9443$ & $296,816.9443$ & 1.002 \\
\hline
\end{tabular}

${ }^{1} \mathrm{LP}_{\mathrm{i}}=$ random-regression animal model using an $\mathrm{LP}$ of order $\mathrm{i}=3,4$, or 5 .

\section{Estimation of parameters}

\section{Variances}

Genetic variances of SCS were estimated for each DIM from 6 to 305. Average genetic variances increased slightly with the order of LP, with values of $0.19,0.21$, and 0.22 , respectively. The trends in genetic variances in all three LP were similar (Figure 1). The largest differences in genetic variances among LP were found at the beginning of lactation. The values decreased from the sixth day after calving up to 60 DIM and increased thereafter to the end of lactation. Similar values of genetic variances were observed for all LP (in the range from 0.13 to 0.24 ) between 60 and 240 DIM.

Trends of genetic variances observed in this study, with the highest values at the beginning of lactation, are similar to those presented by Ptak et al. (2007), Bohmanova et al. (2008), and Samoré et al. (2008). The genetic variances estimated by Mrode and Swanson (2003) showed an increasing trend from 0.04 to 0.06 throughout lactation, with no peaks at the extremes. However, 
the decreasing trend observed for genetic variances at the beginning of lactation in this study is contrary to the results reported by Haile-Mariam et al. (2001). Those authors obtained low values at the beginning, and higher values in the second part of lactation, with values ranging from 0.04 to 0.10 . Differences in estimates obtained from these reported studies are partly associated with the use of alternative methods to transform SCC, and with sire or animal models, orders of LP, and assumptions for residual variances.

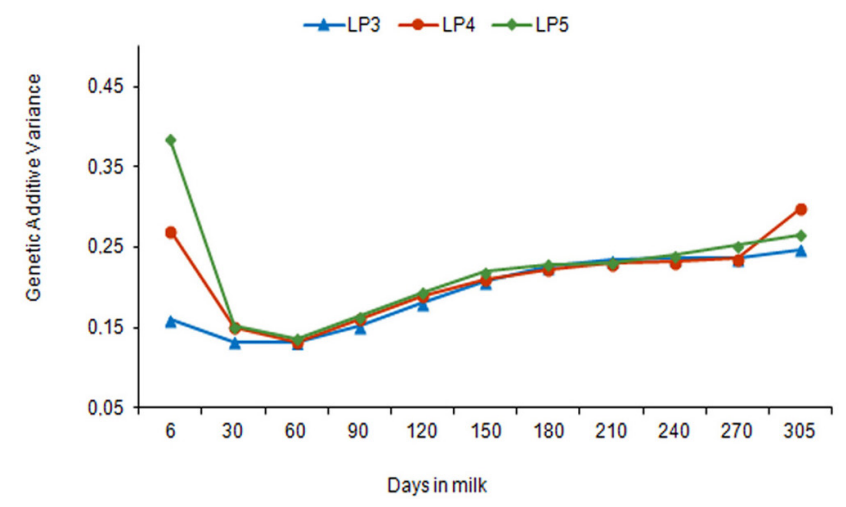

Figure 1. Genetic additive variance estimates for SCS in the first lactation of Holstein cows by fitting LP of orders 3 to 5 .

Permanent environment (PE) variances for SCS were higher and more variable than genetic variances during lactation. PE variances (Figure 2) increased with the order of LP, with average values of $0.98,1.02$, and 1.04 , respectively. The PE variances decreased from their highest to lowest values immediately after calving, and gradually increased up to 210 DIM in all LP. Larger daily differences of PE variance values for the LP were observed between 30 and 150 DIM and at the end of lactation. After 270 DIM, there was little change in the LP3, but this decreased consistently in the LP4 and LP5, whereas the decrease was strongest in the LP5 at 305 DIM. Larger variances of the PE effects estimated immediately after calving are consistent with the results reported by Haile-Mariam et al. (2001) and Ptak et al. (2007). The decreasing trend observed in PE variances at the beginning of lactation in this study is also similar to that reported by Mrode and Swanson (2003) for the first lactation of Holstein cows in UK.

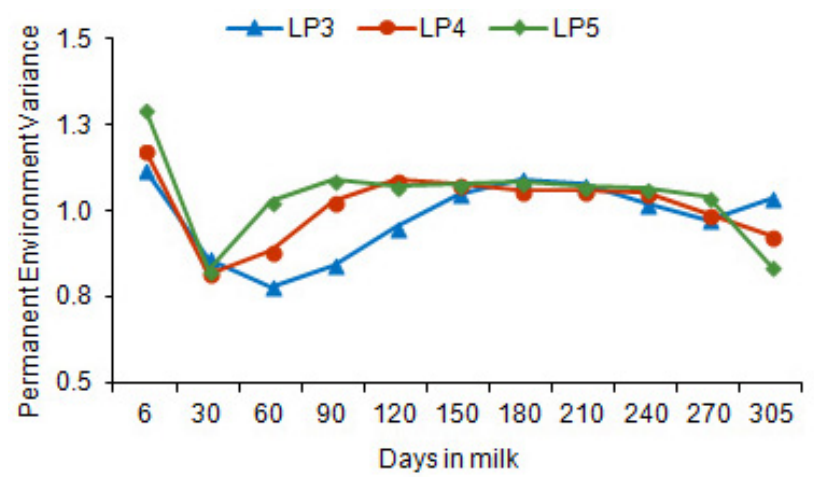

Figure 2. Permanent environment variance estimates for SCS in the first lactation of Holstein cows by fitting LP of orders 3 to 5 . 


\section{Heritability}

Heritability estimates of SCS for DIM are presented in Figure 3. Generally, the heritabilities changed throughout lactation, similarly to the trend observed for genetic variances. The heritability values ranged from 0.06 to 0.14 with means of $0.08,0.09$, and 0.10 for LP3, LP4, and LP5, respectively. Estimates of average heritability in the present study were larger than the estimate of 0.07 reported by Mrode and Swanson (2003), but lower than those reported by Muir et al. (2007), Ptak et al. (2007), Bohmanova et al. (2008) and Samoré et al. (2008), which were equal to 0.16, $0.14,0.21$, and 0.17 , respectively.

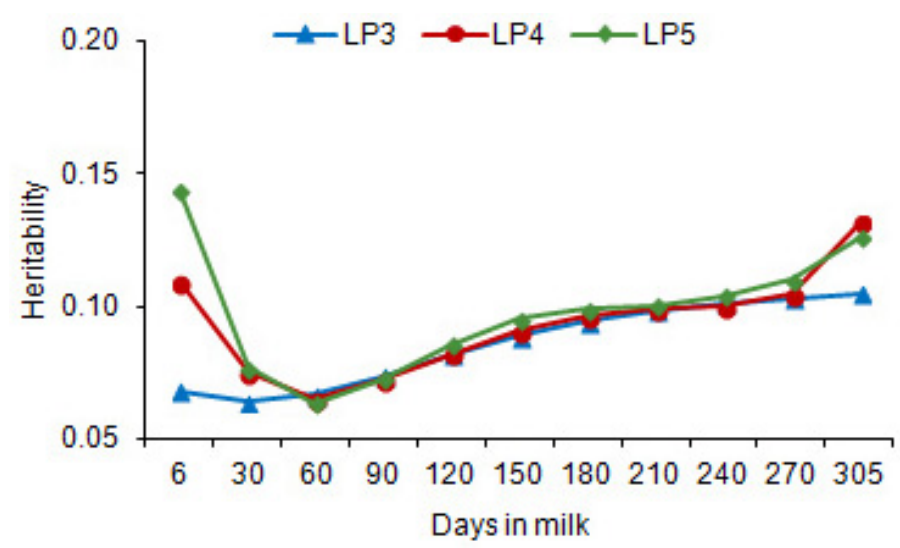

Figure 3. Heritability estimates for SCS in the first lactation of Holstein cows by fitting LP of orders 3 to 5.

Differences between the estimates of heritability obtained from LP were evident at the beginning and end of lactation. Higher heritability estimates occurred at the beginning or end of lactation, especially for LP5. The lowest heritability was observed in the second month of lactation and increased gradually afterwards, with a steep increase after 270 DIM, mainly for LP4 and LP5. With the exception of LP3, the high values of heritability observed at the peripheries are due to high genetic variation at the beginning and low PE variation at the end of lactation.

The pattern observed throughout lactation showing an initial downward slope followed by an increasing trend towards the end of lactation, was similar to the trends reported in estimates by Muir et al. (2007), Ptak et al. (2007), Bohmanova et al. (2008), and Samoré et al. (2008). According to Gernand and König (2014) in their study of clinical mastitis, this increase in heritabilities at the end of lactation is presumably due to data limitations in combination with decreasing incidence of disease. The decreasing trend observed in estimates of heritability at the beginning of lactation is contrary to the results of Haile-Mariam et al. (2001), Mrode and Swanson (2003), and Koivula et al. (2004), who reported increasing heritability of SCS towards the end of lactation.

In this study, residual variances were assumed to be constant throughout lactation and decreased with LP order (Table 2). Assumptions of homogeneous residual variance throughout the course of lactation may have influenced other variance components and therefore the heritability estimates. In their analyses, using LP in RRM, Haile-Mariam et al. (2001), Mrode and Swanson (2003), Ptak et al. (2007), and Bohmanova et al. (2008) reported higher residual variances for SCS in early lactation of Holstein cattle. 


\section{Genetic correlations}

The genetic correlations for SCS among different DIM are presented in the upper diagonal of Tables 3, 4, and 5 for LP3, LP4, and LP5, respectively. Genetic correlations between SCS on different DIM depend on the distance between test days and the stage of lactation. Genetic correlations between SCS were the highest between adjacent DIM (0.83 to 0.99 and $>0.96$ in the mid-lactation) and decreased as the distance between DIM increased.

Genetic correlations between SCS also decreased as the LP order increased, and the highest differences were observed between DIM in the early and late periods of lactation. The lowest correlations were between the 6th and the 305 th DIM, and they were equal to $0.28,-0.06$, and 0.03 for LP3, LP4, and LP5, respectively.

Estimates of genetic correlation in this study were in agreement with the results of most studies, in which the lowest genetic correlations were between SCS at the most distant DIM and the highest, especially during mid-lactation (Haile-Mariam et al., 2001; Mrode and Swanson, 2003; Ødegard et al., 2003; Koivula et al., 2004).

\section{Permanent environment correlations}

The permanent environment correlations for SCS among different DIM (lower diagonal; Tables 3, 4, and 5) showed a similar pattern to the genetic correlations: the highest values were observed between adjacent DIM (0.72-0.99) and declined as DIM became further apart. Permanent environment correlations were slightly lower than the respective genetic correlations, except for between DIM at the extremes of lactation for LP4 and LP5. They also decreased with an increase of the LP order, although this trend was not clear between DIM in late periods of lactation.

Table 3. Genetic correlations (above diagonal), heritabilities (diagonal), and permanent environment correlations (below diagonal) of test day SCS for the first lactation of Holstein cows estimated by LP3.

\begin{tabular}{rccccccccccc}
\hline DIM & 6 & 30 & 60 & 90 & 120 & 150 & 180 & 210 & 240 & 270 & 305 \\
\hline 6 & $\mathbf{0 . 0 7}$ & 0.96 & 0.80 & 0.62 & 0.48 & 0.38 & 0.31 & 0.27 & 0.26 & 0.26 & 0.28 \\
30 & 0.96 & $\mathbf{0 . 0 6}$ & 0.94 & 0.82 & 0.71 & 0.62 & 0.56 & 0.52 & 0.49 & 0.47 & 0.43 \\
60 & 0.80 & 0.94 & $\mathbf{0 . 0 6}$ & 0.96 & 0.90 & 0.85 & 0.80 & 0.76 & 0.72 & 0.67 & 0.57 \\
90 & 0.60 & 0.80 & 0.96 & $\mathbf{0 . 0 7}$ & 0.98 & 0.95 & 0.92 & 0.89 & 0.84 & 0.78 & 0.66 \\
120 & 0.43 & 0.66 & 0.88 & 0.98 & $\mathbf{0 . 0 8}$ & 0.99 & 0.97 & 0.94 & 0.91 & 0.84 & 0.71 \\
150 & 0.31 & 0.55 & 0.80 & 0.94 & 0.99 & $\mathbf{0 . 0 9}$ & 0.99 & 0.98 & 0.94 & 0.88 & 0.75 \\
180 & 0.22 & 0.47 & 0.74 & 0.89 & 0.96 & 0.99 & $\mathbf{0 . 0 9}$ & 0.99 & 0.97 & 0.92 & 0.80 \\
210 & 0.17 & 0.41 & 0.68 & 0.84 & 0.93 & 0.97 & 0.99 & $\mathbf{0 . 0 9}$ & 0.99 & 0.95 & 0.85 \\
240 & 0.15 & 0.37 & 0.62 & 0.78 & 0.86 & 0.92 & 0.95 & 0.98 & $\mathbf{0 . 1 0}$ & 0.98 & 0.91 \\
270 & 0.14 & 0.33 & 0.53 & 0.67 & 0.75 & 0.81 & 0.87 & 0.92 & 0.97 & $\mathbf{0 . 1 0}$ & 0.97 \\
305 & 0.16 & 0.27 & 0.39 & 0.47 & 0.53 & 0.59 & 0.66 & 0.74 & 0.84 & 0.94 & $\mathbf{0 . 1 0}$ \\
\hline
\end{tabular}

\section{Genetic trends}

Figures 4 and 5 depict the mean breeding value (BV) of SCS by birth year (BY) of cows and bulls, respectively. All means showed deviation from the breeding value average of cows born in 2000. Genetic trends were estimated for cows with records (BY ranging from 1990 to 2005) and bulls (BY ranging from 1980 to 1997). 
Table 4. Genetic correlations (above diagonal), heritabilities (diagonal), and permanent environment correlations (below diagonal) of test day SCS for the first lactation of Holstein cows estimated by LP4.

\begin{tabular}{rccccccccccc}
\hline DIM & 6 & 30 & 60 & 90 & 120 & 150 & 180 & 210 & 240 & 270 & 305 \\
\hline 6 & $\mathbf{0 . 1 1}$ & 0.91 & 0.59 & 0.35 & 0.25 & 0.24 & 0.26 & 0.27 & 0.25 & 0.16 & -0.06 \\
30 & 0.87 & $\mathbf{0 . 0 7}$ & 0.87 & 0.69 & 0.60 & 0.57 & 0.56 & 0.55 & 0.51 & 0.43 & 0.22 \\
60 & 0.55 & 0.88 & $\mathbf{0 . 0 6}$ & 0.96 & 0.91 & 0.87 & 0.83 & 0.79 & 0.75 & 0.68 & 0.53 \\
90 & 0.33 & 0.73 & 0.96 & $\mathbf{0 . 0 7}$ & 0.99 & 0.96 & 0.93 & 0.88 & 0.84 & 0.78 & 0.65 \\
120 & 0.21 & 0.62 & 0.90 & 0.98 & $\mathbf{0 . 0 8}$ & 0.99 & 0.97 & 0.93 & 0.89 & 0.84 & 0.70 \\
150 & 0.16 & 0.53 & 0.81 & 0.92 & 0.98 & $\mathbf{0 . 0 9}$ & 0.99 & 0.97 & 0.93 & 0.88 & 0.72 \\
180 & 0.15 & 0.46 & 0.70 & 0.82 & 0.91 & 0.99 & $\mathbf{0 . 1 0}$ & 0.99 & 0.97 & 0.91 & 0.74 \\
210 & 0.16 & 0.39 & 0.58 & 0.70 & 0.81 & 0.91 & 0.98 & $\mathbf{0 . 1 0}$ & 0.99 & 0.94 & 0.77 \\
240 & 0.19 & 0.35 & 0.50 & 0.61 & 0.72 & 0.84 & 0.93 & 0.99 & $\mathbf{0 . 1 0}$ & 0.98 & 0.83 \\
270 & 0.22 & 0.36 & 0.46 & 0.57 & 0.68 & 0.79 & 0.89 & 0.95 & 0.99 & $\mathbf{0 . 1 0}$ & 0.92 \\
305 & 0.22 & 0.42 & 0.55 & 0.62 & 0.69 & 0.76 & 0.87 & 0.85 & 0.88 & 0.94 & $\mathbf{0 . 1 3}$ \\
\hline
\end{tabular}

Table 5. Genetic correlations (above diagonal), heritabilities (diagonal), and permanent environment correlations (below diagonal) of test day SCS for the first lactation of Holstein cows estimated by LP5.

\begin{tabular}{rccccccccccc}
\hline DIM & 6 & 30 & 60 & 90 & 120 & 150 & 180 & 210 & 240 & 270 & 305 \\
\hline 6 & $\mathbf{0 . 1 4}$ & 0.83 & 0.41 & 0.26 & 0.27 & 0.30 & 0.30 & 0.23 & 0.11 & 0.01 & 0.03 \\
30 & 0.72 & $\mathbf{0 . 0 8}$ & 0.83 & 0.68 & 0.62 & 0.59 & 0.57 & 0.54 & 0.47 & 0.39 & 0.31 \\
60 & 0.32 & 0.88 & $\mathbf{0 . 0 6}$ & 0.96 & 0.88 & 0.82 & 0.79 & 0.78 & 0.75 & 0.69 & 0.59 \\
90 & 0.18 & 0.75 & 0.96 & $\mathbf{0 . 0 7}$ & 0.97 & 0.93 & 0.90 & 0.87 & 0.82 & 0.76 & 0.69 \\
120 & 0.16 & 0.62 & 0.85 & 0.96 & $\mathbf{0 . 0 8}$ & 0.99 & 0.96 & 0.92 & 0.84 & 0.77 & 0.73 \\
150 & 0.18 & 0.50 & 0.70 & 0.86 & 0.97 & $\mathbf{0 . 0 9}$ & 0.98 & 0.95 & 0.86 & 0.78 & 0.75 \\
180 & 0.18 & 0.42 & 0.59 & 0.75 & 0.90 & 0.98 & $\mathbf{0 . 1 0}$ & 0.98 & 0.91 & 0.83 & 0.78 \\
210 & 0.17 & 0.38 & 0.53 & 0.68 & 0.82 & 0.92 & 0.98 & $\mathbf{0 . 1 0}$ & 0.97 & 0.91 & 0.81 \\
240 & 0.14 & 0.38 & 0.51 & 0.63 & 0.74 & 0.83 & 0.91 & 0.97 & $\mathbf{0 . 1 0}$ & 0.98 & 0.85 \\
270 & 0.13 & 0.38 & 0.50 & 0.59 & 0.68 & 0.75 & 0.84 & 0.93 & 0.98 & $\mathbf{0 . 1 1}$ & 0.90 \\
305 & 0.22 & 0.36 & 0.43 & 0.53 & 0.65 & 0.75 & 0.84 & 0.91 & 0.95 & 0.96 & $\mathbf{0 . 1 3}$ \\
\hline
\end{tabular}

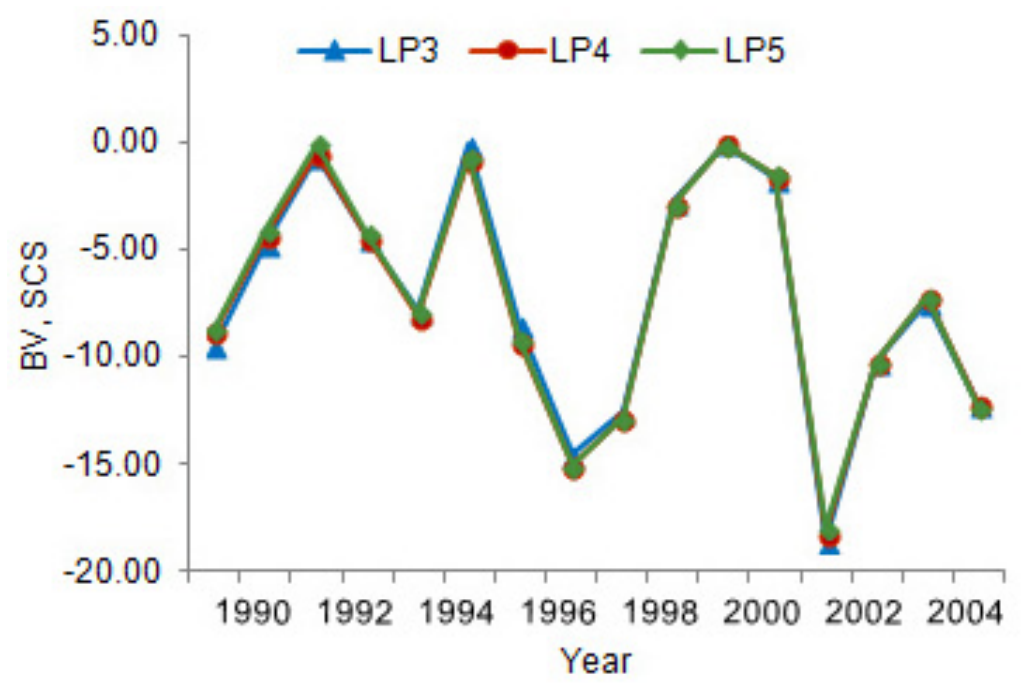

Figure 4. Genetic trend for SCS according to Holstein cow birth year, by fitting LP of orders 3 to 5 . 


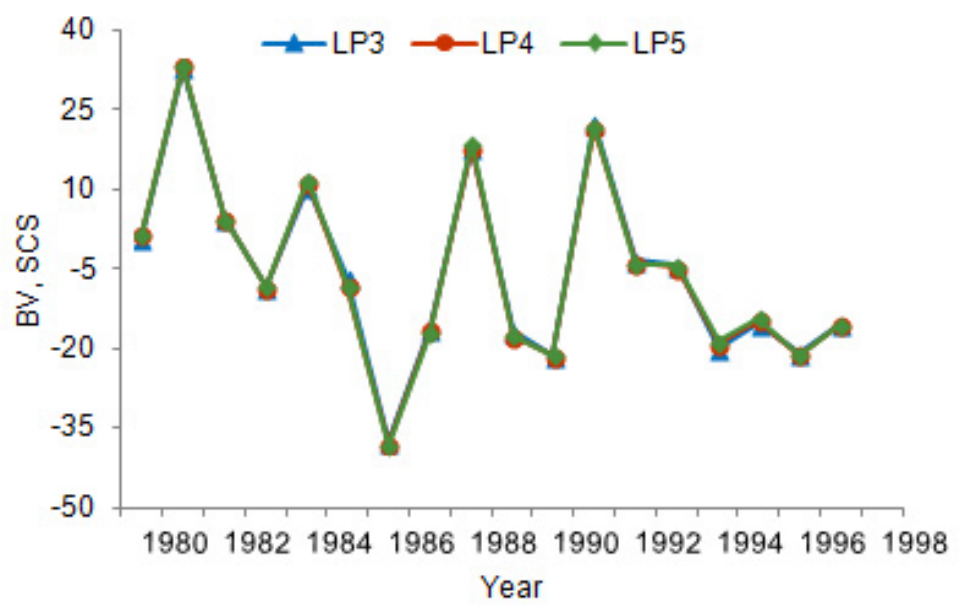

Figure 5. Genetic trend for SCS according to Holstein bull birth year, by fitting LP of orders 3 to 5 .

Regardless of the LP order, changes in BY averages of breeding value estimates for cows and bulls were practically the same; the corresponding linear regression coefficients and $R^{2}$ values are given in Table 6. For all LP, there is an indication of a negative genetic trend for SCS in the population, which is favorable, but it is not significant as indicated by their low $R^{2}$ estimates.

Table 6. Genetic gains estimates for SCS from breeding values of cows and bulls predicted by random-regression
models (RRM) using LP1.
\begin{tabular}{lccc}
\hline G & $\hat{b} \pm s(\hat{b})$ & $R^{2}$ & By period \\
\hline Cows & & & $1990 / 2005$ \\
LP3 & $-0.366 \pm 0.30$ & 0.098 & \\
LP4 & $-0.365 \pm 0.30$ & 0.098 & $1980 / 1997$ \\
LP5 & $-0.385 \pm 0.29$ & 0.108 & \\
Bulls & & 0.180 & \\
LP3 & $-1.375 \pm 0.76$ & 0.170 & \\
LP4 & $-1.383 \pm 0.76$ & 0.164 & \\
LP5 & $-1.370 \pm 0.77$ & & \\
\hline
\end{tabular}

$\mathrm{LP}_{\mathrm{i}}=\mathrm{RRM}$ using an $\mathrm{LP}$ of order $\mathrm{i}=3,4$, or 5 .

Correlation estimates (not shown) between BVs from different LP for SCS were all greater than 0.99 for bulls. This indicates that little change in bull ranking would be expected if any of these LP were used for genetic evaluation of SCS for Holstein bulls in Brazil.

Because no BV for SCS is used in selection decisions against mastitis in Brazil, it is very likely that this trend may be associated with the use of imported sires from countries including SCS in their breeding programs. Mark and Sullivan (2006) reported genetic correlations between SCC in two different countries participating in the Interbull international genetic evaluations ranging from 0.80 to 0.96 .

\section{CONCLUSIONS}

The genetic parameters for SCS estimated in this study are in agreement with results from previous studies, in which heritability was low and the larger genetic correlations were observed 
between SCS in mid-lactation, but decreased to the lowest values between the initial and final DIM. The comparison of genetic parameters estimated by RRMs revealed similar values for heritability and permanent environment correlations among LP models; however, genetic correlations presented a greater range of variation, including a negative value in LP4. Therefore, there was little benefit in fitting a LP order $>3$ to model animal genetic and permanent environment effects. Estimates of variance components found in this study may be used for the implementation of a Best Linear Unbiased Predictor (BLUP) evaluation, although possible heterogeneity of temporary environment variance should be further investigated to evaluate the opportunity to increase accuracy in breeding value estimation for SCS and selection for mastitis resistance in Holstein cows in Brazil.

\section{Conflicts of interest}

The authors declare no conflict of interest.

\section{ACKNOWLEDGMENTS}

We thank the Brazilian Holstein Cattle Breeders Association (ABCBRH), its state affiliates and all their technical staff involved in the collection and management of the data made available and used in this study. This research was developed with the support of Embrapa/SEG MP2 project (\#02.12.02.001.0000).

\section{REFERENCES}

Akaike $\mathrm{H}$ (1974). A new look at the statistical model identification. IEEE Trans. Autom. Control 19: 716-723.

Bohmanova J, Miglior F, Jamrozik J, Misztal I, et al. (2008). Comparison of random regression models with Legendre polynomials and Linear Splines for production traits and somatic cell score of Canadian Holstein cows. J. Dairy Sci. 91: 3627-3638.

Carlén E, Strandberg E and Roth A (2004). Genetic parameters for clinical mastitis, somatic cell score, and production in the first three lactations of Swedish Holstein cows. J. Dairy Sci. 87: 3062-3070.

Costa CN, Cobuci JA, Santos GG, Marques A, et al. (2013). Sumário Nacional de Touros da Raça Holandesa - 2013. Vol. 167. Embrapa Gado de Leite (Documentos), Juiz de Fora.

Gernand E and König S (2014). Random regression test-day model for clinical mastitis: Genetic parameters, model comparison, and correlations with indicator traits. J. Dairy Sci. 97: 3953-3963.

Haile-Mariam M, Goddard ME and Bowman PJ (2001). Estimates of genetic for daily somatic cell count of Australian dairy cattle. J. Dairy Sci. 84: 125-1264.

Halasa T, Huijps K, Østerås O and Hogeveen H (2007). Economic effects of bovine mastitis and mastitis management: A review. Vet. Q. 29: 18-31.

Heringstad B, Klemetsdal G and Ruane J (2000). Selection for mastitis resistance in dairy cattle: a review with focus on the situation in the Nordic countries. Livest. Prod. Sci. 64: 95-106.

INTERBULL (2013). National GES information: Description of National Genetic Evaluation Systems for dairy cattle traits as applied in different Interbull member countries. Available at [http://interbull2.slu.se/www/national_ges_info2/framesida-ges.htm]. Accessed December 12, 2013.

Koivula M, Negussie E and Mantysaari EA (2004). Genetic parameters for test-day somatic cell count at different lactation stages of Finnish dairy cattle. Livest. Prod. Sci. 90: 145-157.

Mark T (2004). Applied genetic evaluations for production and functional traits in dairy cattle. J. Dairy Sci. 87: 2641-2652.

Mark T and Sullivan PG (2006). Multiple-trait multiple-country genetic evaluations for udder health traits. J. Dairy Sci. 89: 4874-4885.

Meyer K (1998). Estimating covariances functions for longitudinal data using a random regression model. Gen. Selec. Evol. 30: $221-240$. 
Miglior F, Muir BL and Van Doormal BJ (2005). Selection Indices in Holstein Cattle of Various Countries. J. Dairy Sci. 88: 1255-1263

Miller RH, Norman HD, Wright JR and Cole JB (2009). Impact of genetic merit for milk somatic cell score of sires and maternal grandsires on herd life of their daughters. J. Dairy Sci. 92: 2224-2228.

Misztal I (2007). AIREMLF90 Program. Available at [http://nce.ads.uga.edu/ ignacy/numpub/blupf90/winbin/zs6/bin/]. Accessed October 21, 2009.

Mrode R, Pritchard TA, Coffey M and Wall E (2012). Joint estimation of genetic parameters for test-day somatic cell count and mastitis in the United Kingdom. J. Dairy Sci. 95: 4618-4628.

Mrode RA and Swanson GJT (1996). Genetic and statistical properties of somatic cell count and its suitability as an indirect means of reducing the incidence of mastitis in dairy cattle. Anim. Breed. Abstr. 64: 847-857.

Mrode RA and Swanson GJT (2003). Estimation of genetic parameters for somatic cell count in the first three lactations using random regression. Livest. Prod. Sci. 79: 239-247.

Muir BL, Kistemaker G, Jamrozik J and Canavesi F (2007). Genetic parameters for a multiple-trait multiple-lactation random regression test-day model in Italian Holsteins. J. Dairy Sci. 90: 1564-1574.

Ødegard J, Klemetsdal G and Heringstad B (2003). Variance components and genetic trend for somatic cell count in Norwegian Cattle. Livest. Prod. Sci. 79: 135-144.

Ptak E, Brzozowski P, Jagusiak W and Zdziarski K (2007). Genetic parameters for somatic cell score for Polish Black-andWhite cattle estimated with a random regression model. J. Anim. Feed Sci. 16: 357-369.

Rupp R and Boichard D (2003). Genetics of resistance to mastitis in dairy cattle. Vet. Res. 34: 671-688.

Samoré AB, Groen AF, Boettcher PJ, Jamrozik J, et al. (2008). Genetic correlation patterns between somatic cell score and protein yield in the Italian Holstein-Friesian population. J. Dairy Sci. 91: 4013-4021. 